\title{
Moving Beyond Narcan: A Police, Social Service, and Researcher Collaborative Response to the Opioid Crisis
}

\author{
Michael D. White ${ }^{1} \cdot$ Dina Perrone ${ }^{2} \cdot$ Seth Watts ${ }^{1} \cdot$ Aili Malm $^{2}$ \\ Received: 2 December 2020 / Accepted: 10 February 2021 / \\ Published online: 3 July 2021 \\ (C) Southern Criminal Justice Association 2021
}

\begin{abstract}
The opioid crisis is the most persistent, long-term public health emergency facing the United States, and available evidence suggests the crisis has worsened during the COVID-19 global pandemic. Naloxone is an effective overdose response that saves lives, but the drug does not address problematic drug use, addiction, or the underlying conditions that lead to overdoses. The opioid crisis is at its core a multidisciplinary, multisystem problem, and an effective response to the crisis requires collaboration across those various systems. This paper describes such a collaborative effort. The Tempe First-Responder Opioid Recovery Project is a multidisciplinary partnership that includes police officers, social workers, substance use peer counselors, public health professionals, police researchers, and drug policy/harm reduction researchers. The project, 10 months underway, trained and equipped Tempe (AZ) police officers to administer Narcan. In addition, a 24/7 in-person "Crisis Outreach Response Team" rapidly responds to any suspected overdose and offers follow-up support, referrals, and services to the individual (and loved ones) for up to 45 days after the overdose. We present preliminary project data including interviews with project managers, counselors, and police officers, descriptions of Narcan administrations in the field, and aggregate data on client service engagement. These data highlight the complexity of the opioid crisis, the collaborative nature of the Tempe project, and the importance of initiating a multidisciplinary, comprehensive response to effectively deal with the opioid problem.
\end{abstract}

Keywords Opioid crisis $\cdot$ Police $\cdot$ Naloxone $\cdot$ Collaborative response

Michael D. White

mdwhite1@asu.edu

Extended author information available on the last page of the article 


\section{Introduction}

The opioid epidemic in the United States has gone through three distinct waves (Centers for Disease Control and Prevention [CDC], 2020). The first wave, beginning in the early 1990s, was driven by a dramatic increase in opioid prescriptions, while the second wave (beginning in 2010) was a consequence of increased heroin use (CDC, 2020). The third and most recent wave, which is tied to increased use of synthetic opioids (especially fentanyl), started in 2013 and has been much deadlier than previous waves. In 2017, 47,600 Americans died from an opioid overdose (National Institute on Drug Abuse, 2020), leading the U.S. Department of Health and Human Services to declare a national public health emergency (Johnson \& Wagner, 2017). In 2018, the number of opioid overdose deaths declined slightly $(46,802$; Wilson et al., 2020). The crisis has worsened during the COVID-19 pandemic, as officials in at least 40 states have reported increases in opioid overdoses and deaths in 2020 (American Medical Association, 2020).

Naloxone administration programs have emerged as an effective live-saving response to opioid overdoses. Naloxone, an opioid antagonist that binds to opioid receptors in the brain, blocks the effects of other opioids (e.g., fentanyl, heroin), reduces the chances of brain damage, and restores "normal breathing" (Rando et al., 2015: 1202). Narcan, a popular brand of intranasal naloxone, works quickly to reverse an overdose, does not result in significant side effects, and does not cause harm if administered to someone who did not use an opioid (Dahlem et al., 2017). Naloxone has been publicly available for several decades, saving countless people's lives.

Because police are often the first to arrive at the scene of an overdose, an increasing number of departments have created police-led naloxone programs, whereby officers are trained to administer the drug to an individual experiencing an overdose (Ronan, 2014). In 2013, Michael Botticelli, Deputy Director of the U.S. National Drug Control Policy stated, "Naloxone, a life-saving overdose reversal drug...should be in the patrol cars of every law enforcement professional across the nation" (Botticelli, 2013, para. 4). Soon after, in 2014, the Bureau of Justice Assistance (2020) created the Law Enforcement Naloxone Toolkit to provide guidance to police agencies seeking to develop a program, and the Police Foundation (2014) created an information sheet/handout about naloxone to give law enforcement agencies "the knowledge it needs to save lives and to improve community relationships" (p. 1). By 2019, 2,500 law enforcement agencies reported their officers carry naloxone (Quinn, 2019).

Despite its effectiveness as a response to reversing an overdose, Narcan does not address problematic drug use, addiction, or the underlying conditions that cause an overdose. In simple terms, Narcan is not enough (Goodison et al., 2019). The opioid crisis is at its core a multidisciplinary, multisystem problem, and an effective response to the crisis requires collaboration across those various systems. A comprehensive response to the opioid crisis will engage practitioners (and researchers) in policing, public health, social work, counseling, harm reduction, and drug policy. The creation of a multidisciplinary collaboration on this 
scale is both daunting and highly complex, but it is critical to effectively combat the opioid crisis. The current study describes such a collaboration.

In October 2019, the city of Tempe, Arizona received a \$2 million grant from the Substance Abuse and Mental Health Services Administration (SAMHSA) to initiate the Tempe First-Responder Opioid Recovery Project (ORP). As part of the project, Tempe police officers have been trained and equipped to administer Narcan. In addition, a 24/7 in-person "Crisis Outreach Response Team" rapidly responds to any suspected overdose (either at the scene or the hospital) and offers follow-up support to the individual/family for up to 45 days after the overdose (e.g., referrals, counseling, recovery services, and transportation). The multidisciplinary partnership includes Tempe police officers, social workers, peer counselors, public health professionals, police researchers from Arizona State University (ASU), and drug policy and harm reduction researchers from California State University, Long Beach (CSULB). In this paper, we describe the project using data from interviews and focus groups with the service providers and police officers, descriptions of Narcan administrations in the field, and aggregate data on client service engagement. These data highlight the complexity of the opioid crisis, the collaborative nature of the Tempe project, and the importance of initiating a multidisciplinary, comprehensive response to effectively deal with the opioid problem.

\section{Prior Research}

\section{The Opioid Crisis and Naloxone}

Naloxone has been a central feature of the response to the opioid crisis for decades. Over the last 25 years, naloxone kits have been distributed to EMTs, firefighters, police officers, and laypersons throughout the U.S and the globe. Law enforcement agencies began to carry naloxone in 2010 , though only about $15 \%$ of U.S. agencies are equipped with and trained to administer naloxone (Quinn, 2019). A handful of research studies in the U.S. and Canada have assessed law enforcement officers (LEO) attitudes about opioid use and naloxone, and the results are mixed. Surveys and focus groups of law enforcement officers in the U.S. and Canada highlight a number of LEO concerns, including expanded liability; proper naloxone administration (Deonarine et al., 2016; Green et al., 2013); fears of accidental exposure to opioids; and increased risk of confrontations with hostile individuals recovering from an overdose (Smyser \& Lubin, 2018). Other studies show some officers believe that responding to opioid overdoses should not be their responsibility and that administering Narcan implies they condone opioid use (Green et al., 2013; Winograd et al., 2019).

When officers carry naloxone, some studies show notable benefits to the officers, to their relationships with the community, and to public safety. Officers report greater job satisfaction and feelings of empowerment and gratification (Dahlem et al., 2017; Smyser \& Lubin, 2018; Wagner et al., 2016). They also describe their programs as improving police-community relationships and increasing overall public safety (Davis et al., 2014; Lurigio et al., 2018; Ray et al., 2015). In one of the few 
empirical studies of a police-led naloxone program, Rando et al., (2015: 1201) concluded "intranasal Naloxone administration by police first responders is associated with decreased deaths in opioid overdose victims."

\section{Moving Beyond Narcan}

Narcan is an effective response to reversing overdoses, but it does little to address the larger problems associated with the opioid crisis. Collaborative, multidisciplinary responses are required to successfully connect people who use opioids (PWUOs) with appropriate services and treatment, which can lead to lower rates of opioid use and fewer overdoses and deaths (CDC, 2020). These partnerships typically involve social outreach groups, treatment providers, public health officials, and sometimes the police. Law enforcement collaborations with service providers to address crimerelated problems are not new. Historically, police-social work partnerships are most common when addressing intimate partner violence and mental illness. A systematic review of the literature between 1979 and 2019 demonstrates that these collaborations have been and continue to be widespread (Patterson \& Swan, 2019).

Such collaborations to address community drug problems primarily began in the 1990s, as police leaders in several agencies sought to link law enforcement, public health, and treatment agencies to address their city's drug problems. Baltimore Police Commissioner Thomas Frazier who served from 1994-2000 is one example. He encouraged officers to refer people who use drugs into treatment and share information about needle-exchange services (Goetz \& Mitchell, 2006). In 2000, the North Carolina (NC) Governor also instituted police-social service collaborations, which created a mechanism for police to connect survivors of domestic violence, those with poor mental health, and those with substance use problems to social workers to address needs (Governor's Crime Commission, 2000).

Many of these early efforts in collaboration did not have the intended impact on use of substances. Goetz and Mitchell (2006) stress that because stakeholders did not have aligned goals and many officers did not buy-in to these initiatives, they were less effective. This is in stark contrast to more recent partnerships, such as Law Enforcement Assisted Diversion (LEAD) and Police Assisted Addiction and Recovery Initiative (PAARI). LEAD is a multi-agency collaboration between police, prosecutors, public defenders, case management agencies, and service providers. Developed in Seattle in 2011, the program seeks to divert those who violate low-level drug laws and/or engage in sex work into appropriate services, in lieu of arrest (LEAD National Support Bureau, n.d.a). An evaluation of the Seattle LEAD program reported a $58 \%$ reduction in recidivism (defined as felony arrests), as clients experienced a greater likelihood of obtaining employment and housing (Collins et al., 2017; Clifasefi et al. 2017). A recent evaluation of LEAD in California reported similarly positive results (Perrone et al., 2020). The process evaluation for the two California sites -LEAD San Francisco and LEAD Los Angeles County -found the "relationships created among partners and their collaborative nature throughout the implementation of LEAD" to be instrumental in the program's success (Malm et al., 2020: 33), and law enforcement buy-in as a necessary component (Magaña et al., forthcoming). In 2016, the National Institute of Justice 
(2016) rated LEAD a promising practice, and since Seattle's implementation of the police-led program, LEAD has been implemented in over 40 sites across the United States (LEAD National Support Bureau, n.d.a).

The Police Assisted Addiction and Recovery Initiative (PAARI, 2020), otherwise known as "Angel programs," started in 2015, and is a police and public health partnership that diverts people who use drugs from the criminal justice system (Goodison et al., 2019). These initiatives provide "training, strategic guidance, support, and resources to help law enforcement agencies nationwide create non-arrest pathways to treatment and recovery" (para. 1). One Angel program in Gloucester, MA referred over 350 people who use drugs into treatment in just one year (Schiff et al., 2017). An estimated 600 Angel programs are currently in practice nationwide.

Police-led partnerships with health or service-providing agencies to address drug problems at the point of an overdose are only recently becoming more common (see Yatsco et al., 2020a). These fall into four categories: multidisciplinary team visits, police visit with referrals, clinician outreach, and location-based outreach (Formica et al., 2018). Each of these program types have the goal of connecting those who survived an opioid overdose to services. In the multidisciplinary team visit model, "a public safety representative (police, fire, EMS) and one or more public health representatives (substance use counselors, social workers, outreach workers) travel together to the residence of the overdose survivor or site of an overdose shortly following the event" (Formica et al., 2018: 45).

A police visits with referrals model involves "police traveling to the residence of the overdose survivor or the site of an overdose shortly following the event. The officer provides... information on support group schedules and addiction treatment options" (Formica et al., 2018: 46). The Houston Emergency Opioid Engagement System (HEROES) collaboration with the Houston police department can be categorized as this type of program. In HEROES, police officers from the Narcotics Division visit those individuals reported to police who survived an overdose (Yatsco et al., 2020b: 3).

In clinician outreach, a substance use counselor receives information about a recent survivor of an overdose from a law enforcement or fire department (Formica et al., 2018). Deputies in Washtenaw County (MI), for example, contact a case manager from their partnering treatment agency immediately after naloxone is administered (Dahlem et al., 2017). The case manager then follows-up with the person who overdosed.

The current study describes a police-led, clinician outreach overdose response and referral program in Tempe, AZ. Much like the Washtenaw County program, the Tempe First-Responder ORP is a multidisciplinary collaboration narrowly focused on opioid overdoses.

\section{Methods and Data}

\section{Research Setting}

Tempe is located southeast of downtown Phoenix and has 192,364 permanent residents (U.S. Census, 2020). Tempe's population is predominantly White $(68 \%)$ and 
Latino (22\%). Tempe is home to Arizona State University (ASU), comprised of approximately 70,000 students who reside and/or attend school in the city. In 2018, Tempe witnessed violent and property crime rates well above national rates at 484.2 and 4,138.0 per 100,000 residents, respectively (FBI, 2020). ${ }^{1}$ The Tempe Police Department (TPD) is medium-sized, employing 350 sworn officers.

\section{The Tempe First-Responder Opioid Recovery Project}

From 2017-2018, the Tempe Fire Department (TFD) responded to 471 suspected incidents of opioid abuse and administered naloxone in $42 \%$ (or 202) of those incidents. Though Tempe police officers often arrived at suspected overdose scenes before TFD, officers did not carry naloxone. In October 2019, TPD received a $\$ 2$ million grant from the Substance Abuse and Mental Health Services Administration (SAMHSA) to initiate the Tempe First-Responder Opioid Recovery Project (ORP). The goals of the four-year project are to:

1. Equip and train TPD officers and key community stakeholders with naloxone;

2. Create a 24/7 "Crisis Outreach Peer Support Response Team";

3. Provide overdose victims and their families with peer-delivered "Post-Crisis Transition Navigation" support to provide recovery and navigation assistance for referrals to treatment services.

The Tempe First-Responder ORP is led by an advisory committee with representatives from the TPD, EMPACT (a comprehensive crisis and community behavioral health services organization), TFD, police researchers from ASU, and drug policy/ harm reduction researchers from California State University, Long Beach (CSULB). The budget includes funding for a project manager (at EMPACT), a full-time Narcan project coordinator in the TPD (a sworn patrol officer), two post-crisis transition navigators (at EMPACT), funds for the purchase and distribution of naloxone nasal spray, funds for counseling and referral services, and funds for comprehensive process and impact evaluations. The TPD project coordinator and the EMPACT project manager meet weekly and the advisory committee meets monthly to discuss progress, challenges, and project next steps.

The TPD provided Narcan training to its first 10 officers on January 28, 2020, and by November 15, 2020, 292 sworn and civilian employees had received the training. In addition, TPD provided Narcan training to 69 community members. The project works as follows. TPD and TFD respond to a 911 call (typically for an unresponsive individual). Whomever arrives first determines whether the individual is experiencing an opioid overdose, and if so, administers Narcan. If the individual recovers and agrees, they are then transported to an emergency room. If a Tempe police officer responds to the overdose, the officer contacts The Tempe First-Responder ORP

\footnotetext{
${ }^{1}$ In 2018, the national violent crime rate was 368.9 per 100,000 citizens, and the property crime rate was 2,199.5 per 100,000 citizens (https://ucr.fbi.gov/crime-in-the-u.s/2018/crime-in-the-u.s.-2018).
} 
hotline, which is staffed 24/7 by counselors at EMPACT (regardless of who administers Narcan -TPD, TFD, or both). The officer provides EMPACT with the relevant information, and a certified peer support specialist responds to the hospital or the survivor's address/location to make initial contact with the person who experienced the overdose (and their loved ones), collect contact information, and introduce them to the program. Within 24 hours, a post-crisis transition navigator follows up in an effort to engage the individual and their loved ones in services for up to 45 days.

\section{The Tempe First-Responder ORP Evaluation}

Researchers at ASU and CSULB are conducting comprehensive process and impact evaluations of the project. The evaluations are guided by six research questions:

1. What do officers think about opioid use and Naloxone, and does the ORP change their attitudes?

2. Does the $O R P$ reduce opioid overdoses in Tempe (and among clients)?

3. Does the $O R P$ lead to enhanced service engagement among clients?

4. Does $O R P$ improve physical health of clients?

5. Does $O R P$ reduce contacts with police (i.e., recidivism)?

6. Does $O R P$ facilitate improvement of client quality of life via service engagement related to housing, employment, education, substance abuse, mental health, and life skills?

The researchers are collecting a range of data to answer the research questions above, including an officer perception survey (pre- and post-program start), city and county data on opioid use and overdoses, qualitative interviews of key program personnel and police officers, interviews with individuals who overdose (and their loved ones), and EMPACT program data on service engagement.

The project has been underway for approximately 10 months, and in the current paper, we present available data that begin to answer several of the core research questions. We review descriptive data regarding the number of Narcan administrations to date (February 10, 2021), characteristics of those who overdosed, and aggregate-level client engagement information gleaned from EMPACT administrative data. Next, we describe qualitative data from interviews with police officers and key program personnel to highlight key aspects of program implementation, most notably officer commitment, collaboration, and communication across partner agencies. $^{2}$ The data presented here demonstrate the complexity of the opioid crisis, the degree of police officer commitment to the program, and the need for a collaborative, multidisciplinary response to address the problem.

\footnotetext{
${ }^{2}$ We conducted interviews and focus groups with line personnel, supervisors/project managers, and command staff in the TPD and EMPACT. We do not use names to protect confidentiality. Line personnel (e.g., EMPACT staff and patrol officers) are designated with a number. Supervisors and command staff are designated with a letter.
} 
Table 1 The Prevalence and Characteristics of Overdose Incidents

\begin{tabular}{ll}
\hline & Percentage (n) \\
\hline $\begin{array}{l}\text { Narcan Administrations to Date }(n=100) \\
\quad \text { Individual survived }\end{array}$ & $81 \%(81)$ \\
Individual died & $11 \%(11)$ \\
$\quad$ Not opioid-related & $8 \%(8)$ \\
Individual Race/Ethnicity & \\
$\quad$ White & $69.8 \%(67)$ \\
Black & $14.6 \%(14)$ \\
Hispanic & $12.5 \%(12)$ \\
Other & $3.1 \%(3)$ \\
Mean Age & 32.1 \\
Individual is Homeless & $27 \%(27)$ \\
\hline
\end{tabular}

\section{Results}

\section{Administrations of Narcan}

The Tempe First-Responder ORP had its first "save" on February 3, 2020, and as of February 10, 2021, Tempe police officers have administered Narcan to 100 individuals who were suspected of experiencing an opioid overdose (see Table 1). Of those 100, 81 individuals responded positively to the Narcan dose(s) and recovered from their overdose. Those 81 individuals were unresponsive, not breathing, and were dying when police arrived at the scene. All 81 survived the overdose because of Narcan. Eleven individuals could not be revived at the scene or hospital. The Narcan was ineffective because the person had already died prior to the officer's arrival. Eight Narcan administrations were deemed ineffective because the person was not experiencing an opioid overdose (one case was cardiac-related; one was related to diabetic issues; six involved drugs other than opiates).

We also collect some basic information about people who have overdosed and received Narcan from a TPD officer. Table 1 shows individuals are predominately White $(69.8 \%)$, with a smaller percentage Black (14.6\%) and Hispanic (12.5\%). Compared to Tempe demographics, Black individuals are over-represented, and Hispanics are under-represented. The mean age is $32.1(\mathrm{SD}=12.3)$, ranging from 16 to 79. Approximately $27 \%$ of the individuals were homeless at the time they experienced the overdose. Last, officers on scene attempt to gather information regarding the type of drug used. Though this information is preliminary, more than $70 \%$ of the overdoses occurred as a result of fentanyl use. Less than $10 \%$ involved heroin, and the rest involved other types of pills (e.g., Percocet, Oxycodone).

\section{Officer Commitment to the Tempe First-Responder ORP}

Officer buy-in is a critical component to an effective collaborative response to the opioid crisis, but as indicated earlier, prior research shows that police officers have 
numerous concerns about carrying and administering naloxone (Deonarine et al., 2016; Green et al., 2013; Smyser \& Lubin, 2018). The officers who participated in our interviews and focus groups, however, demonstrated a strong commitment to the program. One Tempe PD officer describes the sentiment:

There's the defund conversation, and we don't want policing involved in human services and, you know, all this stuff. Most cops will tell you they want nothing to do with homelessness. They want nothing to do with human services. But, no one else has been doing it for a long time. And so, we had to step into that role. But those same people immediately said 'We want you to enforce mask mandates. We want you to enforce, you know, all these rules on the pandemic.' I was like, 'Oh, wait a minute. Which one is it? You know, you're putting us in this bad spot.' And then throw on that, you have the civil unrest, which, there's real hurt, real pain, real issues that we need to deal with. In the middle of that, you have some people who have no interest in peace... And so, the cops are thrown into the middle of all of this, and you can't, you can't win... But at the end of the day, you can respond to this person's OD. They're not talking to you right now, and I can just try to save their lives, help that person, walk away, and feel really good about, you know, myself, what I did, the impact that I had. (Law Enforcement Officer A, October 2020)

Another officer explained commitment to the program in very clear terms:

A cop will not stand over somebody and watch them die, if they have a tool on their belt to fix it. They just won't. ...And they haven't. (Law Enforcement Officer A, October 2020)

The Tempe officers remain bought in despite concerns of contracting COVID-19.

...we're not having cops shy away from using it [Narcan], even during the pandemic, which was something that we were a little bit nervous about ...You're up close and giving compressions... you know, putting chest compressions down and you know the person's expelling all this air... but it's just amazing to see because the cops are just, they're not throwing caution to the wind, but they're just-they're trying to save a life. (Law Enforcement Officer B, October 2020)

Staff at EMPACT also commented on the degree of buy-in among officers.

Well, the level and the rate that the Tempe police are using Narcan is shocking, we're all blown away. ... I'm surprised that they're the first responder that many times, right!? They're there before [Tempe] Fire. That there's that much need. That they're using it that quickly. I think we were telling [name redacted] that we've got six or seven [officers] that have had two uses, and one officer who's had three uses... It's shocking, so there's some interesting dynamic going on and or some interesting desire by the officers to really embrace it and do it. (EMPACT Provider A, October 2020) 
Much of the officer commitment to the program is tied directly to the opportunity to save a life. Officers in other naloxone projects expressed a strong sense of gratification and empowerment after saving a life (Dahlem et al., 2017; Smyser \& Lubin, 2018; Wagner et al., 2016), and Tempe officers echoed those sentiments:

I can say the first time I was standing over somebody and I had it on my belt, it was pretty obvious they were going through an overdose... it was pretty quick how fast I pulled it out... and it's potentially going to save their life right now and basically immediately. To not administer it felt like it went against everything I got in the profession to do and why I continue to do it to this day. You know, chasing people, arresting bad guys, and stuff is all well and good but ultimately, creating a safe, healthy environment for the citizens that you work for is first and foremost. (Law Enforcement Officer \#2, October 2020).

You keeping them alive right there on the spot with the the simple administration of Narcan, gives that person the opportunity to live and to possibly get help and to live a life that they can enjoy. That's all - for me, as an officer, that's all I can ask for - to give someone an opportunity for a better life. Will they take that opportunity? I'm old enough and I've been around long enough to know that you can't make people do anything that they don't want to do, but you can provide them with opportunities. (Law Enforcement Officer \#1, October 2020)

Once they administer Narcan, revive the life, and notify EMPACT, officers have opened the door to opportunities and their role is complete. Officers expressed an appreciation for the partnership with EMPACT, which allows them to make a connection and hand off the individual to folks who have expertise in behavioral health. EMPACT staff acknowledged that appreciation from officers.

It's just the nature of the world with 911, police should be able to hand off and go back to doing police work and let behavioral health do it. And, it's even more further reinforcing that folks like EMPACT saying, 'yeah, this is our space, just get it-just get us the referral, we'll run with it from here.'... They did their part. And now, we should be taking it from here. (EMPACT Provider A, October 2020)

\section{Tempe First-Responder ORP Client Engagement}

Staff from EMPACT sought to provide immediate crisis response to all overdose incidents described above. In some cases, crisis response did not occur because the person either refused transport to the hospital or left the hospital prior to EMPACT arriving. Also, during the first few months of the COVID-19 pandemic, EMPACT staff sometimes had difficulty gaining access to the hospital. Despite these challenges, EMPACT staff provided crisis response in 71 cases, and in 63, 
they were able to make contact with the individual and deliver information about the program. ${ }^{3}$ By November 15, 2020, 34 clients have accepted navigation services, and EMPACT has delivered 213 case management contacts. Service referrals to date include:

- Outpatient treatment services (8)

- Enrollment in state-designated severely mentally ill (SMI) services (16)

- Re-connect to SMI clinic (4)

- Intensive outpatient program (7)

- Residential treatment (7)

- Inpatient hospitalization (6)

- Children services (1)

- Pain management (1)

- Alcoholics Anonymous (3)

- Food stamps (1)

- Housing (1)

- Employment support (3)

- Family support (3)

- Narcan kits given-103 kits to 67 people.

Additional data are being collected to more fully capture the services received by Tempe First-Responder ORP clients, the impact of those services, as well patterns of clients' opioid use (before and after the overdose). Moreover, Tempe PD has not responded to an overdose for the same individual more than once.

This rate of engagement is significantly higher than rates documented in prior research. For example, some studies show that about $25 \%$ of individuals seek treatment after they overdose (e.g., Dahlem et al., 2017; Pollini et al., 2006), and 33\% engage with treatment after an LEO referral (Wagner et al., 2016). Of the 63 individuals who were successfully contacted by EMPACT, 34 (or 54\%) have accepted referrals or services.

\section{The Importance of Collaboration and Communication}

In our interviews and focus groups, both police officers and EMPACT service providers attribute the client engagement successes to the effective collaboration and communication among the partners. One EMPACT service provider explains:

I think the collaboration between both organizations is great because we do work so closely together, that makes the whole process so much easier. When we first started it was more separate. So now, like, I have contact with the

\footnotetext{
${ }^{3}$ By November 15, 2020, Tempe police officers administered Narcan to 67 people. That number increased to 100 by February 10, 2021. There are a handful of other overdoses where the Tempe Fire Department arrived first and administered Narcan. We do not include those cases in the description of Narcan administrations, but many of those cases are also referred to EMPACT as potential participants in the Tempe First-Responder ORP.
} 
officers on phones and stuff... And so, it makes everything run so much more smoothly. (EMPACT Provider 1, October 2020)

These strong partnerships must be cultivated prior to and throughout implementation.

I think it's important that any program, any police department, any fire department understands that that coordination is not magic. Right? You've got to spend the time, and you've got to have the relationships to make that happen... The coordination with the different stakeholders to do stuff that just isn't done otherwise, and the use of peer supports to connect with clients that are not getting connected with... and the resources, you know, the resources to do a $24 / 7$ operation in tons of different locations...big - yeah, big, big, big strength. (EMPACT Provider B, October 2020)

In fact, the agencies met weekly at the start and continue to meet weekly, virtually, to identify challenges, address them, and push forward.

...I still have weekly meetings with [name redacted] as the project director on Tempe. We were having more frequent meetings with [other Tempe PD partners], which we've slowed down because obviously things are working. But we still have that weekly touch point and, and still a bi-weekly or monthly with [name redacted] and with others in Tempe PD. And then, kind of a similar weekly or bi-weekly touch point with the EMPACT staff that are actually delivering the services, doing the work, those types of things. And, ...sometimes there's opportunities to improve or fix or course adjust... having that dual discipline weekly or bi-weekly or regular conversation, I think, frankly, has probably been the biggest secret to success. I think independently, they're all doing great stuff. But getting it to operate as a single program, I think that really was kind of key. (EMPACT Provider A, October, 2020)

While the EMPACT provider above identified frequent conversations among a multidisciplinary team as The Tempe First-Responder ORP's "secret to success," both law enforcement and the service providers noted such smooth communication could not have been possible without a liaison or "boundary spanner" who is familiar with the culture and lexicon of both agencies. For example, having a project manager who works in behavioral health and is a retired police officer could play this role and facilitate the collaboration.

I think you do need that boundary spanner, somebody who can understand both worlds and be that kind of go between. ...I think the role is critical... find your behavior health partner that understands crisis and has the right culture to work with law enforcement. (EMPACT Provider A, October, 2020)

The same EMPACT provider stressed the importance of developing relationships among the different stakeholders.

Invest in the relationship... those guys need to spend a lot of time and energy, making sure that the relationship, the communication all that is built, espe- 
cially if you don't already have that, right? ...I think most folks ignore that, and they go right to operations, and it's a big mess. In my mind, having the relationships is paramount. The rest will come together, sooner or later. And, we can solve anything, if we've got the right relationship. (EMPACT Provider A, October, 2020)

The relationships built among the partners and open lines of communication ensured that obstacles, such as holding in-person trainings and accessing hospitals due to COVID-19, were easily overcome. Both officers and service providers highlighted the hospital access problem as an example of the effective collaboration among partners:

[COVID-19 led to] severe measures and locked everything down. And so, it was very difficult for our EMPACT navigators or crisis response team to get in [to the hospitals]...And so we pivoted pretty_almost overnight. We pivoted, and we started having cops go with the crisis team. And that was kind of their ticket in, because the cop was in uniform. (Law Enforcement Officer B, October 2020)

I think the biggie is that if you don't have regular communication, this would look totally different... EMPACT would have built their version in a vacuum, Tempe would have built theirs in a vacuum... We built it so that it truly was more of a single project with two different components... Then, we just pivoted as we came up with things right, such as the hospital issue, to come up with an easy solution... That would have been a very difficult one to solve. And if we couldn't get into certain hospitals, it fundamentally would have undermined our model... So it allowed us to pivot and problem solve, pretty quick. (EMPACT Provider A, October 2020)

\section{Discussion}

The opioid crisis is the most persistent, long-term public health emergency facing the United States, and available evidence suggests the crisis has worsened during the COVID-19 global pandemic (Center for U.S. Policy, 2020; Sanchez \& Eldeib, 2020). The American Medical Association issued a brief on October 31, 2020 (pg. 1), stating "The AMA is greatly concerned by an increasing number of reports from national, state and local media suggesting increases in opioid- and other drug-related mortality-particularly from illicitly manufactured fentanyl and fentanyl analogs."

Naloxone is a critically important component for responding to overdoses, but naloxone administration programs are too narrowly focused to serve as a stand-alone response to the opioid crisis. The complexity of the problem requires a more holistic, comprehensive response that targets addiction and the underlying conditions associated with opioid use. Goodison et al. (2019: 6) note: "Because law enforcement officers are uniquely positioned to encounter persons in the community who use drugs, especially during times of crisis, they serve as an important conduit through which appropriate interventions can reach the individuals who need them." 
The Tempe First-Responder Opioid Recovery Project reflects the spirit of these ideas, as it involves a partnership between police, social service providers, public health officials, and researchers. We presented preliminary data based on the first 10 months of program operation, and a number of themes emerged that highlight the critical importance of a collaborative, multidisciplinary response.

First and foremost, 81 lives were saved because a Tempe police officer reversed an overdose with Narcan. Many, if not all, of those people would have died if not for the Tempe First-Responder ORP. ${ }^{4}$ Moreover, aggregate data from EMPACT (as of November 15, 2020) shows 34 individuals who overdosed have accepted at least some services, ranging from in-patient hospitalization $(n=6)$ and residential treatment $(n=7)$ to outpatient treatment $(n=15)$ and alcoholics anonymous $(n=3)$. This is notable, as prior studies show much lower rates of service engagement after an overdose (e.g., Dahlem et al., 2017; Wagner et al., 2016). Early results from the Tempe First-Responder ORP indicates the program is nearly doubling that rate of service engagement. The police administration of naloxone is serving as a window for peer counselors to successfully connect with a person who overdosed and to expand their access to services (Yatsco et al., 2020a, b).

Second, it is far too early to offer any definitive statements on program impact, but the early experiences are noteworthy. The Tempe First-Responder ORP's preliminary successes can be measured by law enforcement buy-in, collaboration among agencies and institutions, lives saved, connections made between peer counselors and overdose survivors, and client engagement in services. These early successes were possible because of the strength of the collaboration among project partners. Moreover, our qualitative interviews highlight how the Tempe First-Responder $O R P$ effectively navigates through two public health emergencies: the opioid crisis and COVID-19. The Tempe First-Responder ORP is effectively confronting the challenges presented by both these crises because of a shared goal, buy-in among all partners, effective communication, and strong collaborative relationships. One officer explained:

I think for me the biggest thing is ... the ability for groups to work together when they have a shared goal. And work together very well... you can get a nonprofit, government entity, and educational institutional in a room together, and you can make things work... (Law Enforcement Officer B, October 2020)

Third, the nature of the opioid crisis and the Tempe First-Responder ORP also requires a diverse set of researchers with varied skills. The lead author is a policing researcher who has worked with the TPD for the last five years. He has little experience or knowledge in drug use or policy, let alone harm reduction. But the evaluation of the Tempe First-Responder ORP required that expertise so he put together a team of researchers with the relevant skills and experience to conduct a rigorous evaluation of the program. That rigorous evaluation is grounded in both qualitative and quantitative methodologies. Neither by itself is sufficient. This diverse research

\footnotetext{
4 TFD also responded to many of these overdose scenes but police arrived first. It is unknown how many individuals would have survived the additional seconds or minutes until TFD arrived and administered Narcan.
} 
team and their rigorous evaluation will add to the very small body of literature on partnerships between social service and criminal justice seeking to address the opioid crisis (see Yatsco et al., 2020a).

The current study has a number of limitations that warrant consideration. First, the results presented here are from one project in Tempe, AZ and may not be generalizable. The partnership is unique in terms of the specific collaborators, the target problem, and the program components -though the challenges faced by the Tempe First-Responder ORP are likely not unique. Second, the beginning of the program coincided with the COVID-19 global pandemic, as well as the increase scrutiny of police in summer 2020 following the killings of George Floyd, Breonna Taylor, and others. The extent to which these outside factors influenced the program or the results presented here are not known. Third, the Tempe First-Responder ORP is just underway, and the results presented here are preliminary.

\section{Conclusion}

While it is too early to offer a definitive assessment of program impact, we describe the Tempe First-Responder ORP and the data collected to date as an example of a multidisciplinary, collaborative response to the highly complex and persistent opioid crisis. Each partner plays a critically important role. Police officers respond quickly to overdose scenes and save lives. Those same officers make the crucial notification call to EMPACT. EMPACT peer support specialists respond to make initial contact with individuals and their families. They arrive to the hospital in less than an hour, regardless of when the overdose occurs. EMPACT navigation coordinators then attempt to engage the individual and their families in services, whether it be residential or outpatient treatment, housing, or employment assistance. Through process and impact evaluations, researchers at ASU and CSULB capture and tell the story. That story reflects how the program is implemented, how the program affects those who participate in it (police, social service providers, clients and their families), and whether the program achieves it goals of reducing opioid use, overdoses, and deaths.

\section{$\underline{\text { References }}$}

American Medical Association. (2020). Issue brief: Reports of increases in opioid- and other drug-related overdose and other concerns during COVID pandemic. Retrieved 2 November 2020 from https:// www.ama-assn.org/system/files/2020-11/issue-brief-increases-in-opioid-related-overdose.pdf.

Botticelli, M. (2013). Announcing the opioid overdose toolkit. The White House of Barack Obama. Retrieved 20 April 2020 from https://obamawhitehouse.archives.gov/blog/2013/08/28/announcingopioid-overdose-toolkit.

Bureau of Justice Assistance. (2020). Law enforcement and naloxone toolkit. Retrieved 5 November 2020 from https://bjatta.bja.ojp.gov/tools/naloxone/Naloxone-Background.

Center for U.S. Policy. (2020). Drug overdoses, Deaths appear to increase during pandemic. Retrieved 5 June 2020 from https://centerforuspolicy.org/drug-overdoses-deaths-appear-to-increase-duringpandemic/.

Centers for Disease Control (2020). Understanding the epidemic. Retrieved 5 November 2020 from https:// www.cdc.gov/drugoverdose/epidemic/index.html. 
Clifasefi, S. L., Lonczak, H. S., \& Collins, S. E. (2017). Seattle's Law Enforcement Assisted Diversion (LEAD) Program: Within-subjects changes on housing, employment, and income/benefits outcomes and associations with recidivism. Crime \& Delinquency, 63(4), 429-445. https://doi.org/10.1177/ 001112871668755023

Collins, S. E., Lonczak, H. S., \& Clifasefi, S. L. (2017). Seattle's Law Enforcement Assisted Diversion (LEAD): Program effects on recidivism outcomes. Evaluation and Program Planning, 64, 49-56. https://doi.org/10.1016/j.evalprogplan.2017.05.008

Dahlem, C. H., King, L., Anderson, G., Marr, A., Waddell, J. E., \& Scalera, M. (2017). Beyond rescue: Implementation and evaluation of revised Naloxone training for law enforcement officers. Public Health Nursing, 34(6), 516-521. https://doi.org/10.1111/phn.12365

Davis, C. S., Ruiz, S., Glynn, P., Picariello, G., \& Walley, A. Y. (2014). Expanded access to naloxone among firefighters, police officers, and emergency medical technicians in Massachusetts. American Journal of Public Health., 104(8), e7-e9. https://doi.org/10.2105/AJPH.2014.302062

Deonarine, A., Amlani, A., Ambrose, G., \& Buxton, J. A. (2016). Qualitative assessment of take-home Naloxone program participant and law enforcement interactions in British Columbia. Harm Reduction Journal, 13, 17. https://doi.org/10.1186/s12954-016-0106-1

FBI. (2020). 2018 crime in the United States: Arizona offenses known to law enforcement by city. Retrieved 15 May 2020 from https:/ucr.fbi.gov/crime-in-the-u.s/2018/crime-in-the-u.s.-2017/ tables/table-8/table-8-state-cuts/arizona.xls.

Formica, S. W., Apsler, R., Wilkins, L., Ruiz, S., Reilly, B., \& Walley, A. Y. (2018). Post opioid overdose outreach by public health and public safety agencies: Exploration of emerging programs in Massachusetts. International Journal of Drug Policy 54, 43-50.

Goetz, B., \& Mitchell, R. E. (2006). Pre-arrest/booking drug control strategies: Diversion to treatment, harm reduction and police involvement. Contemporary Drug Problems, 33(3), 473-520.

Goodison, S., Vermeer, M., Barnum, J., Woods, D., \& Jackson, B. (2019). Law enforcement efforts to fight the opioid crisis: convening police leaders, multidisciplinary partners, and researchers to identify promising practices and to inform a research agenda.

Governor's Crime Commission, North Carolina. (2000). Social work and police partnership: A summons to the village strategies and effective practices, North Carolina Department of Crime Control and Public Safety. Retrieved 20 November 2020 from https://digitalcommons.brockport.edu/cgi/viewc ontent.cgi? article $=1000 \&$ context $=$ crj_facpub.

Green, T. C., Zaller, N., Palacios, W. R., Bowman, S. E., Ray, M., Heimer, R., \& Case, P. (2013). Law enforcement attitudes toward overdose prevention and response. Drug and Alcohol Dependence, 133, 677-684. https://doi.org/10.1016/j.drugalcdep.2013.08.018

Johnson, J., \& Wagner, J. (2017). Trump declares the opioid crisis a public health emergency. Washington Post (pp. 10-11).

LEAD National Support Bureau. (n.d.a). About LEAD. https://www.leadbureau.org/about-lead.

Lurigio, A. J., Andrus, J., \& Scott, C. K. (2018). The opioid epidemic and the role of law enforcement officers in saving lives. Victims \& Offenders, 13(8), 1055-1076. https://doi.org/10.1080/15564886. 2018.1514552

Magaña, E., Perrone, D., \& Malm, A., (forthcoming). A process evaluation of San Francisco's Law Enforcement Assisted Diversion (LEAD) program. Criminal Justice Policy Review.

Malm, A., Perrone, D., \& Magaña, E. (2020). Law Enforcement Assisted Diversion (LEAD) External Evaluation: Report to the California State Legislature. http://www.bscc.ca.gov/wp-content/uploads/ CSULB-LEAD-REPORT-TO-LEGISLATURE-1-15-2020.pdf.

National Institute of Justice. (2016). Program profile: Law Enforcement Assisted Diversion (LEAD) Program (Seattle, Washington). CrimeSolutions.gov. https://www.crimesolutions.gov/ProgramDetails. aspx?ID=477.

National Institute on Drug Abuse. (2020). Opioid overdose crisis. National Institutes of Health. Retrieved 20 May 2020 from https://www.drugabuse.gov/drugs-abuse/opioids/opioid-overdose-crisis\#three.

Patterson, G. T., \& Swan, P. G. (2019). Police social work and social service collaboration strategies one hundred years after Vollmer: A systematic review. Policing: An International Journal, 42(5), 863-886. https://doi.org/10.1108/PIJPSM-06-2019-0097

Perrone, D., Malm, A., \& Magaña, E. (2020). Harm reduction policing: An evaluation of Law Enforcement Assisted Diversion (LEAD) in San Francisco. Police Quarterly.

Police Assisted Addiction and Recovery Initiative (2020). About us. Retrieved 5 November 2020 from https://paariusa.org/about-us/. 
Police Foundation. (2014). Five things you need to know about naloxone. Retrieved 20 November 2020 from https://bjatta.bja.ojp.gov/system/files/naloxone/FiveThings_Naloxone_Handout_Final.pdf.

Pollini, R. A., McCall, L., Mehta, S. H., Vlahov, D., \& Strathdee, S. A. (2006). Non-fatal overdose and subsequent drug treatment among injection drug users. Drug and Alcohol Dependence 83(2), 104-110.

Quinn, M. (2019). Most police still don't carry the drug that reverses an opioid overdose. Governing the Future of States and Localities. Retrieved 10 May 2020 from https:/www.governing.com/topics/ public-justice-safety/gov-Naloxone-police-officers-cities.html.

Rando, J., Broering, D., Olson, J. E., Marco, C., \& Evans, S. B. (2015). Intranasal naloxone administration by police first responders is associated with decreased opioid overdose deaths. The American Journal of Emergency Medicine, 33(9), 1201-1204. https://doi.org/10.1016/j.ajem.2015.05.022

Ray, B., O’Donnell, D., \& Kahre, K. (2015). Police officer attitudes towards intranasal naloxone training. Drug and Alcohol Dependence, 146, 107-110. https://doi.org/10.1016/j.drugalcdep.2014.10.026

Ronan P. (2014) Quincy police successfully use Narcan for 300th time. Patriot Ledger. Retrieved 20 May 2020 from http://www.patriotledger.com/article/20141008/News/141006435.

Sanchez, M., \& Eldeib, D. (2020). Overdose deaths have skyrocketed in Chicago, and the coronavirus pandemic may be making it worse. ProPublica Illinois. Retrieved 12 May 2020 from https://www. propublica.org/article/overdose-deaths-have-skyrocketed-in-chicago-and-the-coronavirus-pande mic-may-be-making-it-worse.

Schiff, D. M., Drainoni, M. L., Weinstein, Z. M., Chan, L., Bair-Merritt, M., \& Rosenbloom, D. (2017). A police-led addiction treatment referral program in Gloucester, MA: Implementation and participants' experiences. Journal of Substance Abuse Treatment, 82(Supplement C), 41-47. https://doi. org/10.1016/j.jsat.2017.09.003

Smyser, P. A., \& Lubin, J. S. (2018). Surveying the opinions of Pennsylvania Chiefs of Police toward officers carrying and administering naloxone. The American Journal of Drug and Alcohol Abuse, 44(2), 244-251. https://doi.org/10.1080/00952990.2017.1339053

U.S. Census Bureau. (2020). Quick facts: Tempe city, Arizona. Retrieved 25 April 2020 from https:// www.census.gov/quickfacts/tempecityarizona.

Wagner, K. D., Bovet, L. J., Haynes, B., Joshua, A., \& Davidson, P. J. (2016). Training law enforcement to respond to opioid overdose with naloxone: Impact on knowledge, attitudes, and interactions with community members. Drug and Alcohol Dependence, 165, 22-28. https://doi.org/10.1016/j.druga lcdep.2016.05.008

Wilson N., Karisa M., Seth P., Smith IV, H., Davis N. L. (2020). Drug and opioid-involved overdose deaths — United States, 2017-2018. MMWR Morbidity and Mortality Weekly Report, 69, 290-297. Retrieved 3 November 2020 from https:/www.cdc.gov/mmwr/volumes/69/wr/mm6911a4.htm\# suggestedcitation.

Winograd, R. P., Werner, K. B., Green, L., Phillips, S., Armbruster, J., \& Paul, R. (2019). Concerns that an opioid antidote could "make things worse": Profiles of risk compensation beliefs using the Naloxone-Related Risk Compensation Beliefs (NaRRC-B) scale. Substance Abuse, 1-7.https://doi. org/10.1080/08897077.2019.1616348.

Yatsco, A. J., Champagne-Langabeer, T., Holder, T. F., Stotts, A. L., \& Langabeer, J. R. (2020a). Developing interagency collaboration to address the opioid epidemic: A scoping review of joint criminal justice and healthcare initiatives. International Journal of Drug Policy, 83, 102849. https://doi.org/ 10.1016/j.drugpo.2020.102849

Yatsco, A. J., Garza, R. D., Champagne-Langabeer, T., \& Langabeer, J. R. (2020b). Alternatives to Arrest for illicit opioid use: A joint criminal justice and healthcare treatment collaboration. Substance Abuse: Research and Treatment, 14, 1-8. https://doi.org/10.1177/1178221820953390

Publisher's Note Springer Nature remains neutral with regard to jurisdictional claims in published maps and institutional affiliations. 


\section{Authors and Affiliations}

\section{Michael D. White ${ }^{1} \cdot$ Dina Perrone ${ }^{2} \cdot$ Seth Watts ${ }^{1} \cdot$ Aili Malm $^{2}$}

Dina Perrone

dina.perrone@csulb.edu

Seth Watts

swatts12@asu.edu

Aili Malm

aili.malm@csulb.edu

1 Center for Violence Prevention and Community Safety, Arizona State University, 411 N Central Ave, Phoenix, AZ 85004, USA

2 School of Criminology, Criminal Justice, and Emergency Management, California State University Long Beach, 1250 Bellflower Boulevard, Long Beach, CA 90840, USA 